\title{
A Role for G-proteins and Inositol Phosphate Signalling in Dictyostelium discoideum Slug Behaviour
}

\author{
By P. K. DARCY AND P. R. FISHER* \\ Microbiology Department, La Trobe University, Bundoora 3083, Melbourne, Australia
}

(Received 1 February 1989; revised 10 April 1988; accepted 21 April 1989)

\begin{abstract}
Phototaxis by Dictyostelium discoideum slugs was disoriented in the presence of pertussis toxin, suggesting a role for pertussis-toxin-sensitive G-proteins in slug behaviour. The decrease in orientation accuracy was dependent on the concentration of this bacterial toxin. Pertussis toxin did not significantly affect slug thermotaxis, while cholera toxin had no significant effects on either slug phototaxis or thermotaxis. The addition of micromolar concentrations of lithium salts $(\mathrm{LiCl}$ or $\mathrm{LiBr})$ resulted in disorientation of both phototaxis and positive thermotaxis by slugs. The corresponding sodium salts had no effect on slug behaviour, confirming that the effects were specific to lithium ions. The effects of lithium ions suggest a role for inositol phosphates as possible second messengers in Dictyostelium slug behaviour. Except for slight impairment of thermotaxis by D-sphingosine, we found no effects on slug behaviour of either phorbol 12-myristate 13-acetate or sphingolipids. We thus found little pharmacological evidence for a role in slug signal transduction of the diacylglycerol branch of the inositol lipid pathway.
\end{abstract}

\section{INTRODUCTION}

The life cycle of the cellular slime mould Dictyostelium discoideum presents unique opportunities to study eukaryotic cell and molecular biology at both the unicellular and multicellular levels of organization (Loomis, 1982). During aggregation by chemotaxis to form the multicellular state, Dictyostelium amoebae process chemoattractant (cAMP) signals in a manner analogous to higher eukaroyotes via activation of G-proteins and increased intracellular concentrations of the second messengers cGMP, inositol-trisphosphate (IP3) and $\mathrm{Ca}^{2+}$ (McRobbie, 1986; Jannsens \& van Haastert, 1987; Newell et al., 1988; Gerisch, 1987).

Although less widely studied, sensory transduction in the multicellular 'slug' stage of the D. discoideum life cycle seems to be based on the same molecular processes as in the unicellular amoeboid stage (Fisher et al., 1984). This leads to the expectation that G-proteins and phosphatidylinositol lipid metabolism might play a role in transmembrane signalling in $D$. discoideum slugs. The striking effects on slug orientation behaviour of fluoride ions have been known for some time (Dohrmann et al., 1984a) and, as is the case in other organisms (Sternweis \& Gilman, 1982), may be explained by the action of aluminofluoride on G-proteins involved in processing behavioural signals in slugs. We report here that pertussis toxin, a specific inhibitor of G-proteins in higher eukaryotes (Stryer \& Bourne, 1986), impairs slug orientation during phototaxis (but not thermotaxis).

In $D$. discoideum, as in other organisms, $\mathrm{Li}^{+}$ions specifically disrupt phosphoinositide signalling by inhibiting the regeneration of inositol via dephosphorylation of IP3 and other inositol phosphates (Worley et al., 1988; Leitz \& Muller, 1986; van Lookeren Campagne et al., 1988). We show here that $\mathrm{Li}^{+}$ions impair slug orientation during both phototaxis and positive thermotaxis, consistent with a possible role for IP3 as an intracellular second messenger in slug behaviour.

\footnotetext{
Abbreviations: IP3, inositol trisphosphate; PIP $_{2}$, phosphatidylinositol bisphosphate; PMA, phorbol 12myristate 13-acetate.
} 


\section{METHODS}

Chemicals. D-Sphingosine, sphingosylphosphorylcholine, lithium and sodium salts, and cholera toxin were obtained from Sigma. Pertussis toxin was supplied by Dr P. Marley in vehicle buffer $[50 \%(\mathrm{w} / \mathrm{v})$ glycerol, $0.2 \%$ (w/v) $\mathrm{NaHCO}_{3}, 1.46 \%$ (w/v) $\mathrm{NaCl}, 0.18 \%$ (w/v) L-lysine] from the Commonwealth Serum Laboratories, Melbourne, Australia.

Strains and culture conditions. D. discoideum strain X22 was grown in association with Klebsiella aerogenes on nutrient SM agar at $21.5^{\circ} \mathrm{C}$ as previously (Fisher $e$ t al., 1981; Fisher \& Williams, 1982).

Phototaxis and thermotaxis experiments. These were done as previously (Fisher et al., 1981; Fisher \& Williams, 1982). Amoebae were washed free of bacteria and resuspended in Bonner's salt solution (per litre: $0.6 \mathrm{~g} \mathrm{NaCl}$, $0.75 \mathrm{~g} \mathrm{KCl}, 0.4 \mathrm{~g} \mathrm{CaCl}_{2} .2 \mathrm{H}_{2} \mathrm{O}$ ) at a density of about $2.5 \times 10^{8}$ amoebae $\mathrm{ml}^{-1}$. A $10 \mu \mathrm{l}$ volume of the amoebal suspension was spread over a $1 \mathrm{~cm} \times 1 \mathrm{~cm}$ origin in the centre of each water agar plate supplemented with the pharmacological agent being tested.

Plates were incubated for phototaxis experiments in the light at $21.5^{\circ} \mathrm{C}$ for $48 \mathrm{~h}$ in individual black PVC boxes with a $2 \mathrm{~mm}$ hole drilled in the side as previously (Fisher et al., 1981; Fisher \& Williams, 1982). For thermotaxis plates were incubated for $72 \mathrm{~h}$ in individual black PVC containers (without holes) on the surface of an insulated aluminium heat bar at temperatures ranging from 1 to 8 (arbitrary units referred to henceforth as T1, T2 ..T8). The heat bar was the same design as that used previously, for which the temperature gradient at the agar surface under the same conditions was $0 \cdot 2{ }^{\circ} \mathrm{C} \mathrm{cm}^{-1}$, with temperatures at the centres of the plates ranging from $14{ }^{\circ} \mathrm{C}$ to $28^{\circ} \mathrm{C}$ (Fisher \& Williams, 1982).

Quantitative behavioural measurements. Slug trails were transferred to clear PVC discs and stained with Coomassie Blue as previously to obtain a permanent record of the result (Fisher et al., 1981). Start and end points of trails from each disc were digitized using a Summagraphics M1201 digitizing tablet connected to a Force Microforce 2 computer. Estimates of the accuracy of phototaxis and thermotaxis were calculated by means of directional statistics as previously (Fisher et al., 1981; Fisher \& Williams, 1982).

The statistical methods were based on the von Mises distribution, an analogue for directional data of the familiar bell-shaped normal distribution. The von Mises distribution has two parameters - a mean direction $\mu$ and a concentration parameter $\kappa$ that measures the concentration of individual directions around the mean. In no case was the mean direction of travel significantly different from the direction towards the light source in phototaxis, towards the warmth in positive thermotaxis or towards the cold in negative thermotaxis. $\kappa$ was used in this work, as previously (Fisher et al., 1981; Fisher \& Williams, 1982), as a measure of the accuracy of slug orientation in phototaxis and thermotaxis. $\kappa$ ranges from a value of 0 in the case of no orientation in any particular direction to $\infty$ in the case of perfect orientation. We followed the previously used convention of assigning negative values of $\kappa$ to significant negative thermotaxis (Fisher \& Williams, 1982).

\section{RESULTS}

\section{$G$ proteins may play a role in slug behaviour}

In higher eukaryotes fluoride ions combine with trace amounts of aluminium to activate the $\alpha$ subunits of $\mathrm{G}_{\mathrm{s}}, \mathrm{G}_{\mathrm{i}}, \mathrm{G}_{\mathrm{o}}$ and transducin (Sternweis \& Gilman, 1982; Stryer \& Bourne, 1986). In D. discoideum fluoride alters both phototaxis and thermotaxis by slugs (Dohrmann et al., 1984a), perhaps by interacting with G-protein(s). Since pertussis and cholera toxins specifically ADPribosylate G-proteins in higher eukaryotes, we examined $D$. discoideum slug behaviour in the presence of these toxins. The results in Figs 1 and $2(a)$ show that the accuracy of slug phototaxis decreased as pertussis toxin concentrations increased from $20 \mathrm{ng} \mathrm{ml}^{-1}$ to $200 \mathrm{ng} \mathrm{ml}^{-1}$. This suggests the possible involvement of a pertussis-toxin-sensitive G-protein in photosensory transduction in slugs.

Thermotaxis by $D$. discoideum slugs is maximally positive at temperatures near the growth temperature (T4 to T5) and becomes less accurate at higher and lower temperatures, finally becoming insignificant and then negative around T2 and T8 (Fisher \& Williams, 1982). Even at the highest concentration tested $\left(200 \mathrm{ng} \mathrm{ml}^{-1}\right)$ pertussis toxin had little effect on slug thermotaxis at any temperature on the heat bar (Fig. 3). Neither slug phototaxis nor thermotaxis were significantly altered by the presence of cholera toxin at concentrations up to $1 \mu \mathrm{g} \mathrm{ml}^{-1}$ (Figs $2 b$ and 3 ).

\section{Inositol phosphates may play a role in slug behaviour}

In $D$. discoideum amoebae, as in other organisms, IP3 triggers release of intracellular bound calcium which in turn appears to regulate the accumulation of cGMP and the cytoskeleton (Newell et al., 1988; Europe-Finner \& Newell, 1985, 1986a, b, 1987). Since $\mathrm{Li}^{+}$ions disrupt IP3 
(a)

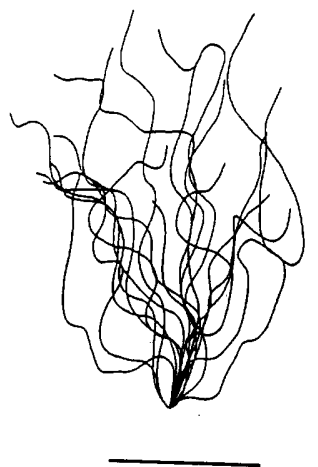

(b)

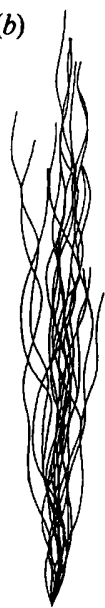

Fig. 1. Phototaxis by slugs of strain X22 in the presence or absence of pertussis toxin. Amoebae $\left(2.5 \times 10^{6}\right)$ were inoculated onto a $1 \mathrm{~cm}^{2}$ origin in the centre of a water agar plate $(a)$ with or $(b)$ without $200 \mathrm{ng}$ pertussis toxin $\mathrm{ml}^{-1}$. After $48 \mathrm{~h}$ incubation at $21.5^{\circ} \mathrm{C}$ slug trails were transferred to PVC discs, stained and digitized. The direction of the light source was from the top of the figure and digitized trails are plotted from a common origin. Bar, $1 \mathrm{~cm}$.
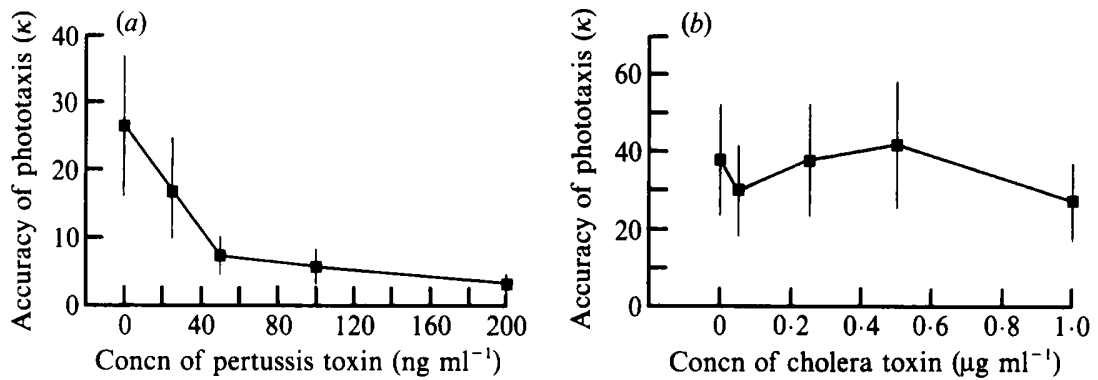

Fig. 2. Effect of pertussis and cholera toxins on the accuracy of phototaxis by X22 slugs. The amoebae were inoculated onto water agar containing $(a)$ pertussis or $(b)$ cholera toxin at the indicated concentrations. Other details as for Fig. 1. Bars represent $90 \%$ confidence limits.

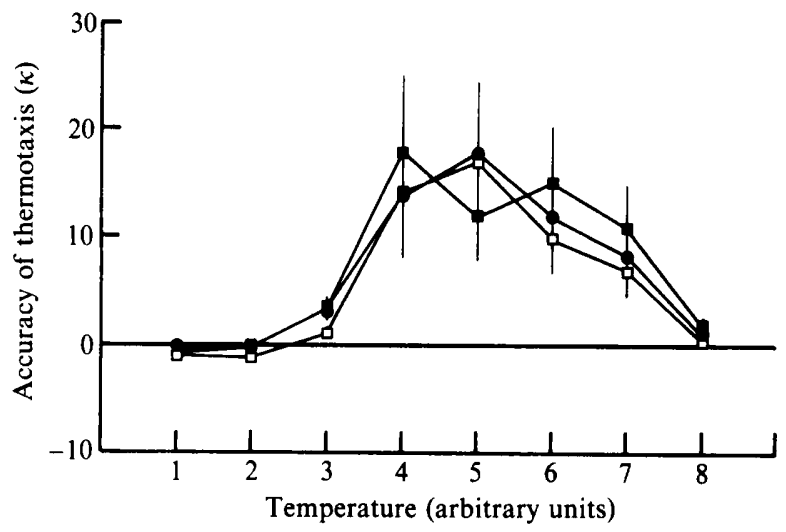

Fig. 3. Effect of pertussis and cholera toxins on thermotaxis by X22 slugs. Amoebae $\left(2.5 \times 10^{6} \mathrm{~cm}^{-2}\right)$ were inoculated onto unsupplemented water agar $(\square)$, or water agar containing $200 \mathrm{ng}$ pertussis toxin $\mathrm{ml}^{-1}(\mathrm{O})$, or $1 \mu \mathrm{g}$ cholera toxin $\mathrm{ml}^{-1}(\square)$. Plates were incubated for $72 \mathrm{~h}$ on the heat bar as described in Methods, with agar surface temperatures (arbitrary units) ranging from 1 at the cold end to 8 at the warm end. After incubation, slug trails were transferred to PVC discs and stained wth Coomassie Blue before digitizing. Bars represent $90 \%$ confidence limits. 

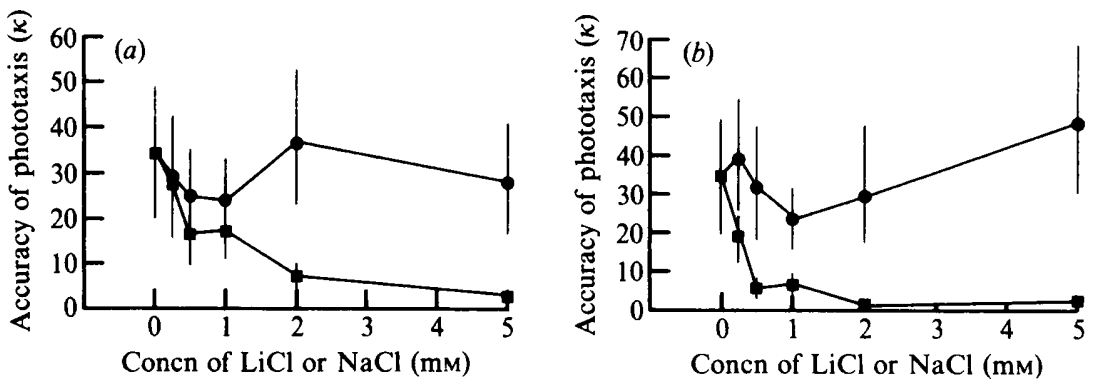

Fig. 4. Effect of lithium salts on the accuracy of phototaxis by X22 slugs. The cell density was $2.4 \times 10^{6}$ amoebae $\mathrm{cm}^{-2}$. The agar contained at the indicated concentrations $(a) \mathrm{LiBr}(\square)$ or $\mathrm{NaBr}(\mathrm{O}),(b) \mathrm{LiCl}$ ( $\square$ ) or $\mathrm{NaCl}(\mathrm{O})$. Other details as for Fig. 1.
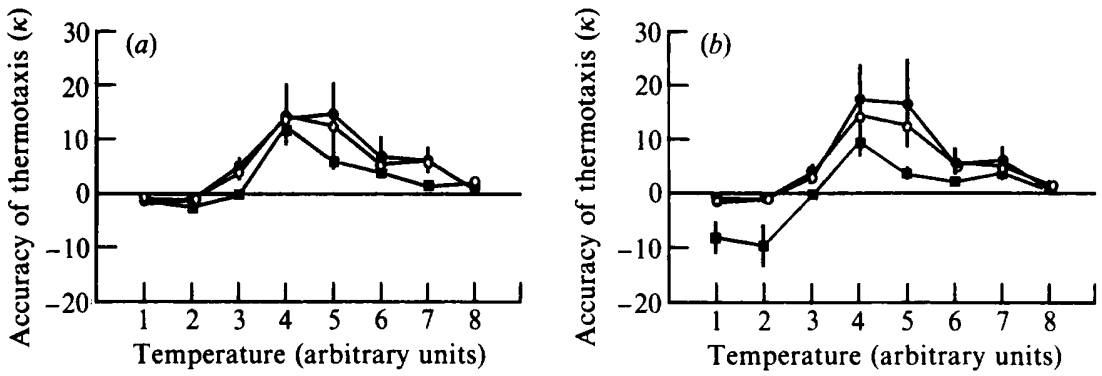

Fig. 5. Effect of lithium salts on thermotaxis by X22 slugs. Amoebae $\left(2.4 \times 10^{6} \mathrm{~cm}^{-2}\right)$ were inoculated onto unsupplemented water agar $(O)$ or water agar containing $(a) 5 \mathrm{~mm}-\mathrm{LiCl}(\square)$ or $\mathrm{NaCl}(O),(b)$ $5 \mathrm{mM}-\mathrm{LiBr}(\square)$ or $\mathrm{NaBr}(\mathrm{O})$. Other details as for Fig. 3.

metabolism, we examined the effects of lithium salts on $D$. discoideum slug behaviour. Micromolar concentrations of $\mathrm{LiBr}$ and $\mathrm{LiCl}$ impaired both slug phototaxis (Fig. $4 a, b$ ) and positive thermotaxis (Fig. $5 a, b$ ), while the corresponding sodium salts had no effect. Negative thermotaxis at $\mathrm{T} 2$ was significantly stronger in the presence of $\mathrm{Li}^{+}$ions, while the temperature at which slugs switched from positive to negative thermotaxis was shifted towards the growth temperature (Fig. 5). As in the case of phototaxis, the effects of $\mathrm{Li}^{+}$ions on thermotaxis were concentration dependent (e.g. Fig. $6 a, b, c)$, with half-maximal inhibition occurring at concentrations of $500 \mu \mathrm{M}$ or less. Like sensory transduction mutations and other pharmacological agents (Fisher \& Williams, 1982; Dohrmann et al., 1984a,b), $\mathrm{Li}^{+}$had least effect on thermotaxis at high temperatures (T8) (Fig. 5).

As well as IP3, hydrolysis of phosphatidylinositol bisphosphate (PIP ${ }_{2}$ ) releases diacylglycerol which, in other eukaryotes, also plays a second-messenger role by activating protein kinase $C$ in the cell membrane (Kikkawa \& Nishizuka, 1986). Since the lysosphingolipids D-sphingosine and sphingosylphosphoryl choline inhibit protein kinase $\mathrm{C}$ in human platelets (Hannun \& Bell, 1987), while phorbol esters such as phorbol 12-myristate 13-acetate (PMA) activate it (Kikkawa \& Nishizuka, 1986), we examined whether these compounds affected slug behaviour. Except for impairment of positive thermotaxis by D-sphingosine (Fig. 7), no significant difference was detected in slug behaviour in the presence or absence of phorbol ester (up to $5 \mu \mathrm{M}$ ) or lysosphingolipids (up to $100 \mu \mathrm{M}$ ) (not shown). These results provide little pharmacological evidence for but do not exclude the possibility that the diacyl glycerol branch of the inositol phospholipid pathway is important in intracellular signalling in slugs. 

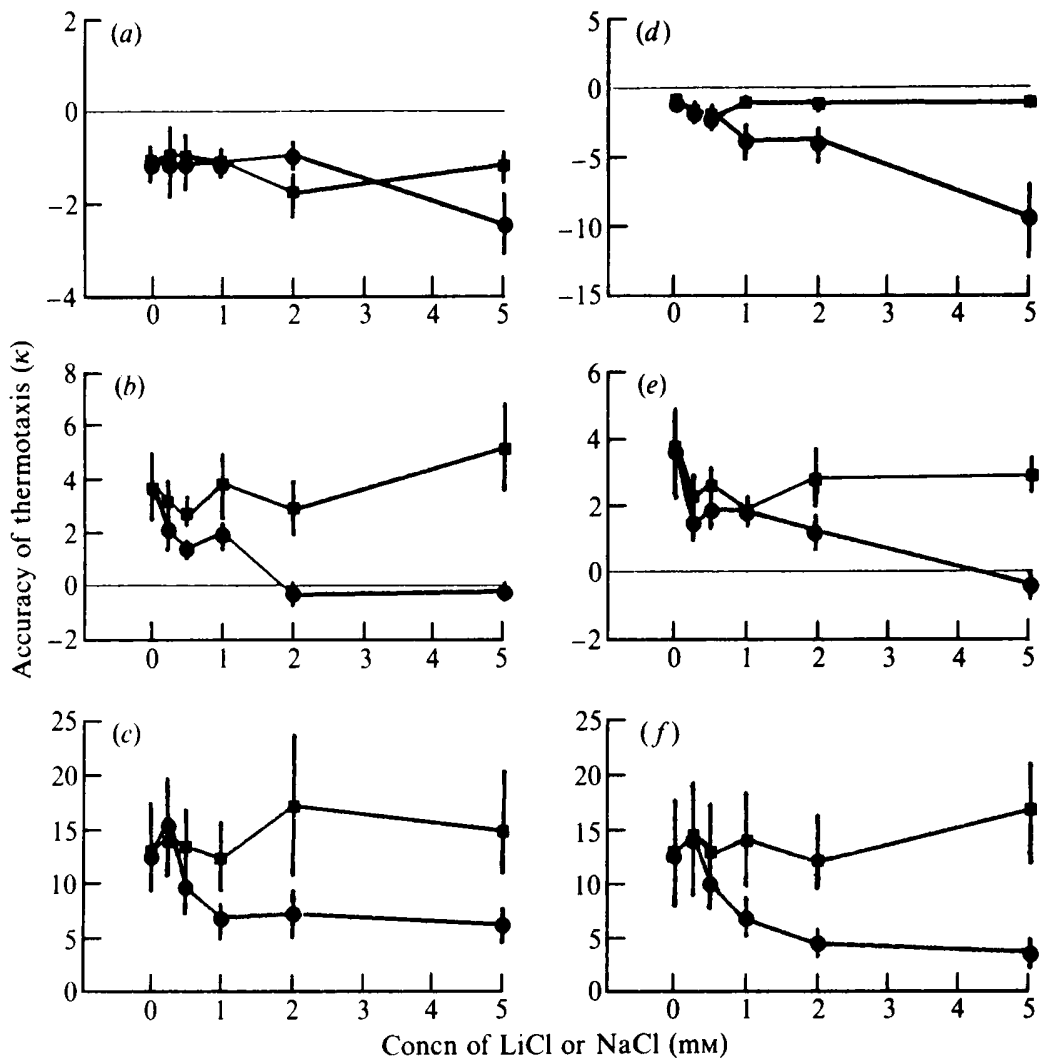

Fig. 6. Concentration dependence of the effect of lithium on slug thermotaxis at $(a, d) \mathrm{T} 2,(b, e) \mathrm{T} 3$ and $(c, f)$ T5. Details as for Fig. 5 except that the agar contained $\mathrm{Li}^{+}(O)$ or $\mathrm{Na}^{+}(\square)$ at the indicated concentrations as either the chloride salt $(a, b, c)$ or the bromide salt $(d, e, f)$.

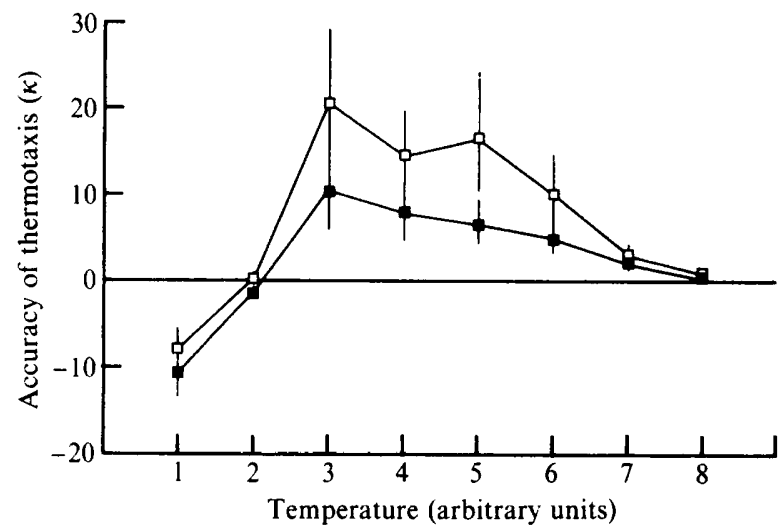

Fig. 7. Influence of D-sphingosine on the accuracy of thermotaxis by $\mathrm{X} 22$ slugs. The cell density was $2.5 \times 10^{6}$ amoebae $\mathrm{cm}^{-2}$ on water agar with $(\square)$ or without $(\square) 80 \mu \mathrm{M}$-D-sphingosine. Other details as for Fig. 3.

\section{DISCUSSION}

The use of pharmacological agents provides an initial approach to studying the potential importance of specific target molecules and pathways in intracellular signalling in slugs. EGTA, for example, has a profound effect on slug phototaxis and thermotaxis (Dohrmann et al., 1984a), 
consistent with an important role in intracellular signalling in slugs for either transmembrane $\mathrm{Ca}^{2+}$ fluxes or IP3 mobilization of intracellular $\mathrm{Ca}^{2+}$. In a similar vein, the data presented in this paper, combined with earlier work, suggest the possible involvement of G-proteins and IP3 metabolism in signal transduction in slugs.

Pertussis and cholera toxins and fluoride ions (as aluminofluoride) are known in other organisms to affect intracellular signalling by acting on G-proteins. The dramatic effects of fluoride ions on slug behaviour were reported previously (Dohrmann et al., 1984a). While slug behaviour was indifferent to the presence of cholera toxin, pertussis toxin significantly impaired phototaxis (Figs 1 and 2). In higher eukaryotes cholera toxin activates $G_{S}$ but does not affect the other classes of $G$ protein. Pertussis toxin and fluoride on the other hand are less specific in that they act on several different kinds of $G$ protein (Kikkawa \& Nishizuka, 1986). The greater specificity of cholera toxin might explain why it fails to affect slug phototaxis whereas both fluoride ions and pertussis toxin do. Leichtling et al. (1981) identified a $42 \mathrm{kDa} \mathrm{G}_{\mathrm{s}}$-like GTPbinding protein in $D$. discoideum that can be ADP ribosylated by cholera toxin. Our results indicate that this protein is unlikely to be important in signal transduction in slugs. Alternatively it may be inaccessible in vivo to cholera toxin because, for example, of the inability of the toxin to penetrate the $D$. disoideum membrane.

Pertussis toxin affects slug phototaxis much less dramatically than does fluoride (Dohrmann et al., 1984a). While both slug phototaxis and thermotaxis are altered in the presence of fluoride, the effects on thermotaxis are less pronounced (Dohrmann et al., 1984a). If the same were true for pertussis toxin, it might be difficult to detect a difference between thermotaxis in the presence and absence of the toxin. Alternatively, pertussis-toxin-sensitive G-protein(s) might be involved in slugs only in phototransduction, at a point before the signalling pathway converges with that for thermotaxis (Fisher et al., 1984). Taken together, the effects of fluoride and pertussis toxin indicate that G-proteins transduce extracellular signals in $D$. discoideum slug behaviour. This conclusion is consistent with mounting evidence for G-protein signalling in the unicellular amoeboid stage of the $D$. discoideum life cycle (Newell et al., 1988; Ludérus $e t$ al., 1988; Snaar-Jagalska et al., 1988; Kesbeke et al., 1988; Europe-Finner et al., 1988).

In mammalian cells G-proteins can activate hydrolysis of phosphatidylinositol bisphosphate, releasing IP3 into the cytosol and diacylglycerol in the membrane. Both products act as second messengers, IP3 by mobilizing intracellular bound $\mathrm{Ca}^{2+}$ and diacyl glycerol by activating protein kinase C. PMA, a protein kinase $\mathrm{C}$ activator, was shown recently to inhibit by up to $50 \%$ the first spike of the cAMP-stimulated light-scattering change in aggregation-competent amoebae (Thiery et al., 1988). In vitro, PMA reduces an ATP- and $\mathrm{Ca}^{2+}$-dependent decrease in the number of cAMP receptors in membrane preparations from $D$. discoideum amoebae (Ludérus et al., 1988).

We found little pharmacological evidence for diacylglycerol and protein kinase $\mathrm{C}$ signalling in slugs and, in particular, found no effect of PMA on slug behaviour, or indeed on aggregation and later development (not shown). However, our results do not exclude a role for protein kinase $C$ in either aggregating amoebae or slugs. Indeed, it remains possible that the effects of Dsphingosine on thermotaxis are mediated by inhibition of protein kinase $\mathrm{C}$. There is considerable evidence from other sources that extracellular cAMP signals might regulate slug tip position, and by this means slug behaviour, in a manner analogous to the way they determine the location of aggregation centres earlier in development (Fisher et al., 1984). The effects of PMA on the cAMP responses of amoebae may be insufficient to markedly influence either aggregation or the behaviour of the multicellular slugs.

$\mathrm{Li}^{+}$ions perturb IP3-signalling by inhibiting phosphatases that dephosphorylate the IP3 and regenerate inositol for formation of new $\mathrm{PIP}_{2}$. Several $D$. discoideum inositol phosphate phosphatases are inhibited in vitro by $\mathrm{Li}^{+}$with half-maximal concentrations ranging from $0.24 \mathrm{mM}\left(\operatorname{Ins}(1,4,5) \mathrm{P}_{3}\right.$ phosphatase) to $2.5 \mathrm{mM}$ (van Lookeren-Campagne et al., 1988). Our observation that similar concentrations of $\mathrm{Li}^{+}$specifically impair slug phototaxis and positive thermotaxis suggests that IP3 is an intracellular second messenger in slug behaviour. This is consistent with the mounting evidence for IP3 signalling in the responses of aggregating amoebae to cAMP (Newell et al., 1988; Europe-Finner \& Newell, 1985, 1986a, b, 1987). 
We are grateful to Dr P. Marley of the Commonwealth Serum Laboratories for his generous gift of the pertussis toxin. This work was supported by a grant from the Australian Research Grants Scheme.

\section{REFERENCES}

Dohrmann, U., Fisher, P. R., Brüderlein, M. \& Williams, K. L. (1984a). Transitions in Dictyostelium discoideum behaviour: influence of calcium and fluoride on slug phototaxis and thermotaxis. Journal of Cell Science 65, 111-121.

Dohrmann, U., Fisher, P. R., BRÜDERlein, M., LACKNER, B. \& Williams, K. L. (1984b). Arachidonic acid and related molecules affect the behaviour of Dictyostelium discoideum slugs. Journal of General Microbiology 130, 2685-2698.

Europe-FinNer, G. N. \& Newell, P. C. (1985). Inositol 1,4,5-triphosphate induces cyclic GMP formation in Dictyostelium discoideum. Biochemical and Biophysical Research Communications 130, 11151122.

Europe-Finner, G. N. \& Newell, P. C. (1986a). Inositol 1,4,5-triphosphate induces calcium release from a nonmitochondrial pool in amoebae of Dictyostelium. Biochimica et biophysica acta 887, 335340.

Europe-Finner, G. N. \& Newell, P. C. (1986b). Inositol 1,4,5-triphosphate and calcium stimulate actin polymerization in Dictyostelium discoideum. Journal of Cell Science 82, 41-51.

Europe-Finner, G. N. \& Newell, P. C. (1987). GTP analogues stimulate inositol triphosphate formation in Dictyostelium. Journal of Cell Science 87, 513-518.

Europe-Finner, G. N., Ludérus, M. E. E., SMall, N. V., VAN Driel, R., ReYMond, C. D., Firtel, R. A. \& Newell, P. C. (1988). Mutant ras gene induces elevated levels of inositol tris- and hexakisphosphates in Dictyostelium. Journal of Cell Science 89, 13-20.

FisheR, P. R. \& Williams, K. L. (1982). Thermotactic behaviour of Dictyostelium discoideum slug phototaxis mutants. Journal of General Microbiology 128, 965-971.

Fisher, P. R., Smith, E. \& Williams, K. L. (1981). An extracellular chemical signal controlling phototactic behaviour by $D$. discoideum slugs. Cell 23, 799-807.

Fisher, P. R., Dohrmann, U. \& Williams, K. L. (1984). Signal processing in Dictyostelium discoideum slugs. Modern Cell Biology: A Review Series 3, 197248.

GerisCH, G. (1987). Cyclic AMP and other signals controlling development and differentiation in Dictyostelium. Annual Review of Biochemistry 56, 853-879.

Hannun, Y. A. \& Bell, R. M. (1987). Lysosphingolipids inhibit protein kinase $\mathrm{C}$ : implications for the sphingolipidoses. Science 235, 670-673.

JANNSENS, P. M. W. \& VAN HAastert, P. J. M. (1987). Molecular basis of transmembrane signal transduction in Dictyostelium discoideum. Microbiological Reviews 51, 396-418.

KesbeKe, F., SNAar-Jagalska, B. E. \& VAN HAastert, P. J. M. (1988). Signal transduction in Dictyostelium fgdA mutants with a defective inter- action between surface cAMP receptor and a GTPbinding regulatory protein. Journal of Cell Biology 107, 521-528.

KikKaWA, U. \& Nishizuka, Y. (1986). The role of protein kinase $\mathrm{C}$ in transmembrane signalling. Annual Review of Cell Biology 2, 149-178.

Leichtling, B. H., Coffman, D. S., Yaeger, E. S. \& RICKENBERG, H. (1981). Occurrence of the adenylate cyclase 'G-protein' in membranes of Dictyostelium discoideum. Biochemical and Biophysical Research Communications 102, 1187-1195.

LeITZ, T. \& Muller, W. A. (1986). Evidence for the involvement of PI-signalling and diacyl glycerol second messengers in the initiation of metamorphosis in the hydroid Hydractinia echinata Fleming. Developmental Biology 121, 82-89.

van LoOKeren Campagne, M. M., ERneuX, C., van EIJK, R. \& VAN HaAsterT, P. J. M. (1988). Two dephosphorylation pathways of inositol 1,4,5-triphosphate in Dictyostelium discoideum homogenates. Biochemical Journal 254, 343-350.

LoOMIS, W. F. (editor) (1982). The Development of Dictyostelium discoideum. New York: Academic Press.

Ludérus, M. E. E., Reymond, C. D., van HaAstert, P. J. M. \& VAN DRIEL, R. (1988). Expression of a mutated ras gene in Dictyostelium discoideum alters the binding of cyclic AMP to its chemotactic receptor. Journal of Cell Science 90, 701-706.

McRobrie, S. J. (1986). Chemotaxis and cell motility in the cellular slime moulds. CRC Critical Reviews in Microbiology 13, 335-375.

Newell, P. C., Europe-Finner, G. N., Small, N. V. \& LIU, G. (1988). Inositol phosphates, G-proteins and ras genes involved in chemotactic signal transduction of Dictyostelium discoideum. Journal of Cell Science 89, 123-127.

SNAAR-JAGalsKa, B. E., Jokabs, K. H. \& VAN HAastert, P. J. M. (1988). Agonist stimulated high affinity GTP-ase in Dictyostelium membranes. FEBS Letters 236, 139-144.

Sternweis, P. C. \& Gilman, A. G. (1982). Aluminum: a requirement for activation of the regulatory component of adenylate cyclase by fluoride. Proceedings of the National Academy of Sciences of the United States of America 79, 4888-4891.

STRYER, L. \& BOURNE, H. R. (1986). G proteins: a family of signal transducers. Annual Review of Cell Biology 2, 391-419.

ThIERY, R., KLEIN, R. \& TATISCHEFF, I. (1988). Phorbol 12-myristate 13-acetate modulates the cAMP-induced light-scattering response of a Dictyostelium discoideum cell population. FEBS Letters 241, 149-153.

Worley, P. F., Heller, W. A., Synder, S. H. \& BARABAN, J. M. (1988). Lithium blocks a phosphoinositode-mediated cholinergic response in hippocampal slices. Science 239, 1428-1429. 